\title{
CHEMICAL FACTORS LIMTITIĆ GROWTH OF PHYTOPLANKTON IN LAKE VICTORIA
}

\author{
By G. R. Fish, East African Fisheries Research Organization, Jinja, Uganda
}

(Received for publication on 28th September, 1955)

The problem of phytoplankton production in tropical waters differs from its counterpart in temperate regions in several important respects. The higher temperature and stronger radiation that are usually found within the tropics are the primary factors responsible. It is well known that certain species of planktonic algae are limited to cold water. The wellmarked seasonal changes that occur in temperate latitudes afford an opportunity for the development of both stenothermal and eurythermal organisms at different times of the year in the same lake. There is a good deal of data available to show that fluctuations in the population of certain planktonic alge are controlled by limiting concentrations of various chemical nutrients, e.g. phosphorus and nitrogen [2], silica [3]. However, Ruttner [1] in a recent review of limnological problems, states that the overall production of phytoplankton is usually limited by low temperature in temperate lakes although, in winter, light is frequently a limiting factor. Hutchinson's conclusions, from a study of phytoplankton growth in Linsey Pond [4], were that fluctuations in growth could not be explained merely in terms of chemical nutrient deficiencies. Riley has made several important observations on this subject. He showed that, on Georges Bank, plankton populations are at a minimum during the annual period of lowest radiation [5]. A theoretical analysis was also made by Riley et al of the seasonal changes in phytoplankton in Korean waters [6]. The conclusion reached, after a study of 450 samples taken during the period 1931-33 and the relevant meteorological data, was that nutrient salts determined the time, duration and magnitude of fluctuations in the phytoplankton population during the summer and autumn, but that the mid-winter minimum and the vernal burst of growth were controlled by radiation.

There is a formidable weight of evidence, therefore, showing that change in population of phytoplankton is controlled largely by climatic conditions and that nutrient deficiencies may be a controlling factor only during relatively short periods.
These conclusions are restricted, however, to lakes and seas which experience large annual climatic variations. Within the tropics, water temperatures are high and uniform throughout the year, although minor fluctuations may occur.

Similarly, day length is uniform and the mid-day sun is always near the vertical, so providing maximum penetration of light into the water. Climatic conditions in the tropics are therefore unlikely to impose limits on production.

Investigations on the problem of phytoplankton productivity in the waters of Lake Victoria have been pursued since 1949. Observations from the shallow bays and inlets showed that no annual cycle of phytoplankton occurred. In view of the favourable climatic conditions found in this area, factors limiting growth of phytoplankton were sought in the form of deficiencies in chemical nutrients dissolved in the water.

Chemical analyses were made at frequent intervals to determine any changes in the concentration of the inorganic constituents of the water. Mackereth [7], discussing the utilization of phosphorus by Asterionella, concluded that water analyses could be of value by indicating those nutrients which are not limiting in concentration. Analyses of the water were therefore made at frequent intervals during 1950 and 1951 . They showed the presence of silica at a concentration of 3-4 p.p.m. Phosphates and the inorganic compounds were usually found to be below the limit of detectability (i.e. 0.05 p.p.m. and 0.1 p.p.m. respectively in our system of analysis). However, the presence of these two salts was often recorded and therefore must be present, on such occasions, in amounts in excess of the requirements of the phytoplankton [8].

Positive evidence regarding limiting nutrients was sought, using the well-known method of adding various nutrients to lake water samples and observing changes in the phytoplankton population. Calcium, nitrogen and phosphorus 
were tried singly and in various combinations. No increase in the growth of phytoplankton was observed. In fact, a sharp decrease in population was usually found. Further investigations showed that the experimental conditions introduced new factors, the effect of which appeared to mask that of nutrient change in the medium. More detailed experiments of this type in the laboratory were not possible because attempts to grow some of the more important planktonic alga of Lake Victoria in artificial culture did not meet with success.

Agar cultures of Chlorella, a green alga, and of Anabrena, a blue-green alga, were then obtained from elsewhere. Members of these genera are common in the plankton of Lake Victoria and it was decided to use these cultures in some preliminary experiments. These experiments were devised to determine which nutrients were limiting the growth of phytoplankton in the lake water.

\section{METHODS}

Pure bacteria-free cultures of Chlorella pyrenoidosa Chick and Anabona cylindrica Lemm. were obtained from Dr. G. E. Fogg, University College, London. The wholly inorganic medium which was used in the experiments with these algæ had the following composition in the case of the Anabcena culture :-

\begin{tabular}{|c|c|c|}
\hline Magnesium sulphate & & 0.2 gms. \\
\hline Potassium phosphate & . & $0.2 \mathrm{gms}$. \\
\hline Calcium chloride . & & $0.1 \mathrm{gms}$. \\
\hline Ferrous sulphate $\quad \ldots$ & . & 0.4 mgns. as Fe. \\
\hline Ammonium molybdate & & 0.1 mgms. as Fe. \\
\hline Boric acid $\quad \ldots \quad \ldots$ & & 0.1 mgms. as $B$. \\
\hline Manganese sulphate & $\cdots$ & 0.1 mgms. as $\mathrm{Mn}$. \\
\hline Copper sulphate . . & $\cdots$ & 0.01 mgms. as $\mathrm{Cu}$. \\
\hline $\begin{array}{l}\text { Zinc sulphate } \\
\text { Pyrex distilled water }\end{array}$ & $\cdots$ & 0.01 mgms. as $\mathrm{Zn}$. \\
\hline
\end{tabular}

The same medium was used for Chlorella with the addition of :-

oftasistmm interte

200 c.c. of culture medium in a 250 c.c. Ehrlenmeyer flask were used in all experiments. The flasks were suspended on a wire framework attached to a window but out of the path of direct sunlight. Each was aerated continuously by a slow stream of filtered air.

All material and apparatus were sterilized by autoclaving at $15 \mathrm{lb}$. pressure for 15 minutes and the usual precautions were observed during assembly and inoculation to prevent bacterial contamination.
At the conclusion of each experiment, the state of the cultures was evaluated visually. Then the dryweight of the algæ in each flask was estimated, in the case of Anabana, by filtering the medium through a paper (Green's Hyduro No. 995) and weighing the dried residue. The Chlorella proved difficult to filter and these cultures were centrifuged and the cells, thus separated, were dried on filter paper. Drying was carried out using a hot-air oven at a temperature of $110^{\circ} \mathrm{C}$. In certain cases, the organic material, both dissolved and finely suspended, in the filtrate was estimated using acidified potassium permanganate.

\section{RESULTS}

A preliminary experiment showed that good growth of the Chlorella and Anabana was obtained in the inorganic culture medium but that there was negligible growth in lake water, even with the addition of calcium, phosphate or nitrate. Very dense cultures were obtained, however, using lake water enriched with the salts comprising the inorganic medium. While an enrichment of the lake water with the constituents of the inorganic medium both singly and in various combinations might have been the logical course of future investigations, it was decided that a better method would be to omit individual constituents from the fully enriched lake water. If any doubt arose that poor growth in any particular medium was caused by an experimental deficiency, then the replacement of the omitted constituent would prove the point. This safeguard on the deductions from the experimental results was deemed important.

Media were prepared consisting of lake water enriched with all the various constituents of the inorganic medium except one. It can be seen from the results in Table $I$, that the omission of calcium, iron, molybdenum, manganese, copper, boron and zinc salts had relatively little effect on the algal growth. Omission of magnesium sulphate, potassium phosphate or nitrate from the enrichment medium had a markedly adverse effect.

Cultures $P$ and $B$ were each divided into two parts. The first of each was supplied with magnesium chloride but no change was observed in the condition of the culture. The second was supplied with sodium sulphate and a vigorous growth of the algæ was obtained within a few days. It was concluded that the lake water contained adequate amounts of all the nutrients required for plant 
growth with the exception of sulphate, phosphate, and, in the case of the non-nitrogenfixing alga, nitrate. Nine further experiments were completed using lake water collected at different times of the year from different parts of the lake and at different depths. The above conclusions were confirmed in all cases.

The effect of sulphate deficiency on the cultures was more marked than the dry weights indicate. Cultures deficient in sulphate were pale, and though growth continued to some extent, the lack of chlorophyll was obvious even to the most casual observer.

Table II shows again that the nutrients in least supply in the lake water are sulphate, phosphate and nitrate. The Anabona culture No, 3 for instance gives almost as high a yield as culture No. 12 although only sulphate and phosphate had been added to the lake water. In this experiment, the nitrogen present in the lake water is insufficient to support more than a slight growth of Chlorella. However, Chlorella cultures 1-6 show that no marked increase in growth occurs unless phosphate is available. Chlorella cultures 7 and 10 show that a deficiency of either of these nutrients gives rise to the same amount of growth, far below that of the control. It may be seen, however, that the Anabena cultures give a higher dry weight in the absence of phosphate than of sulphate (Anabana 7 and 10).

On this occasion, therefore, it seemed that the most important nutrient deficiency in the lake water, as far as the nitrogen fixing alge were concerned, was sulphate.

Sterility precautions were completely relaxed in one experiment (see Table III) in order to estimate the role, if any, of bacterial metabolism. It seems that the nitrogen supply is augmented under these conditions, for the yields of Chlorella were considerably higher than in the other experiments. Less reliance, however, can be placed on the dryweight figures, as bacteria and fungi, although not obvious, may have contributed to them. The comparison of these weights shows the importance of sulphate and phosphate (see cultures 6), and in the case of Anabiena, there is a greater effect shown by a sulphate as compared with a phosphate deficiency (cultures 2-5). The Chlorella cultures $4,5,7,8$ indicate a similar tendency.

Rodhe [2] described a successful method for the determination of iron in the waters of
Lake Sharsjon using cultures of Scenedesmus. He concluded that this method is more sensitive than a purely chemical one but troublesome and time-consuming in operation. Reproducible results, even with the same culture, could not be obtained and so an accurate estimation of iron is only possible when a closely graded control series is grown together with the sample culture. An important advantage of the method is that only biologically available iron is measured. An attempt was made to see if a similar quantitative method could be used to evaluate the nutrient status in lake water. The experimental results are shown in Table IV.

Anabana culture 5 shows that the addition of $0.2 \mathrm{mgms}$. $\mathrm{MgSO}_{4}$ in 200 c.c. is insufficient to overcome sulphate as a primary limiting factor in the lake water. Extrapolation of the graph of the dryweights of Anabona in cultures 2, 4 and 5 against the amount of sulphate added, indicates that a sulphate concentration of just over 1 p.p.m. is already present in the lake water. This result is of the same order as that found by purely chemical methods [8]. Anabcena cultures 9-12 show that the sulphate requirements must be met before a response to added phosphate is found. Increase of all other nutrients is clearly of minor importance to Anabrna. The Chlorella culture 9 shows that no growth of this alga is obtained unless nitrate is supplied. After nitrate, phosphate is indicated as the next nutrient in short supply in the lake water. (Chlorella cultures 16, 17.) The best growth is shown by culture 13 where sulphate, phosphate and nitrate are in adequate supply. All other mineral requirements of Chlorella are met by salts already present in the lake water.

Many accounts of culture methods of algac have shown that natural waters frequently contain a growth-promoting substance which is not present in artificial media. Pringsheim [9] for instance, recommends the addition of soil solution to an artificial medium when cultivating certain alga.

The experiments recorded in Table $\mathrm{V}$ show that Anabana grows better in media made up with lake water than in media made up in distilled water. As it is unlikely that the distilled water contained any deleterious substances which might cause a reduction in the growth of Anabrna, one must conclude that the iake water contains some growth-promoting substances. (The experiments on the effect of these substances on the growth of Chlorella 
Table I.-The Growth of Cultures from 17-9-52 to 23-10-52 in Lake or Distilled Water WITH VARIOUS INORGANIC ADDITIONS

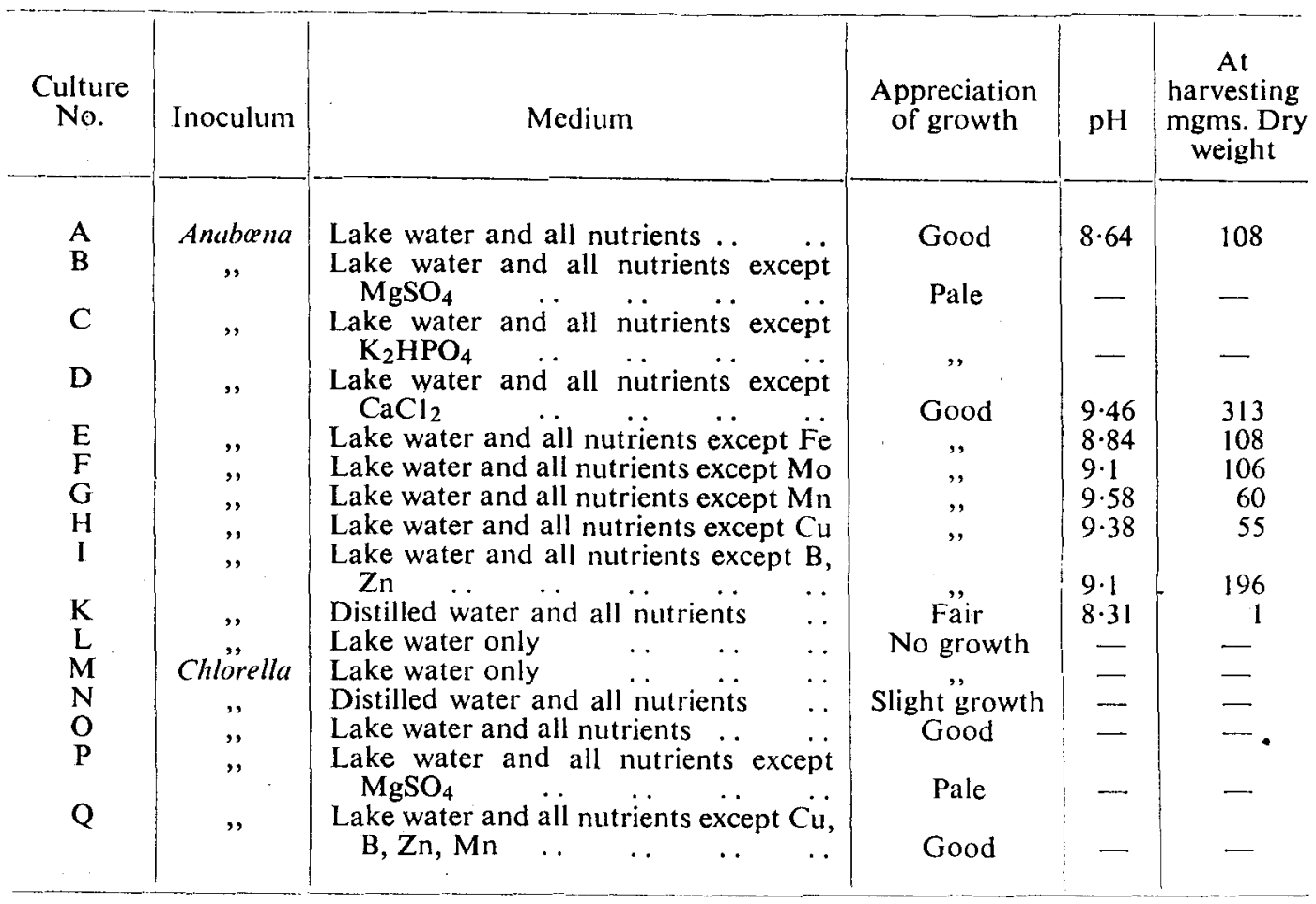

Table II.-The Growth of Cultures from 17-9-53 to 23-12-53 in Lake or Distilled Water WITH VARIOUS INORGANIC ADDITIONS

(During the harvesting of the algce in cultures No. 8 a small amount of material was lost. The dry weights recorded for these cultures is therefore slightly low)

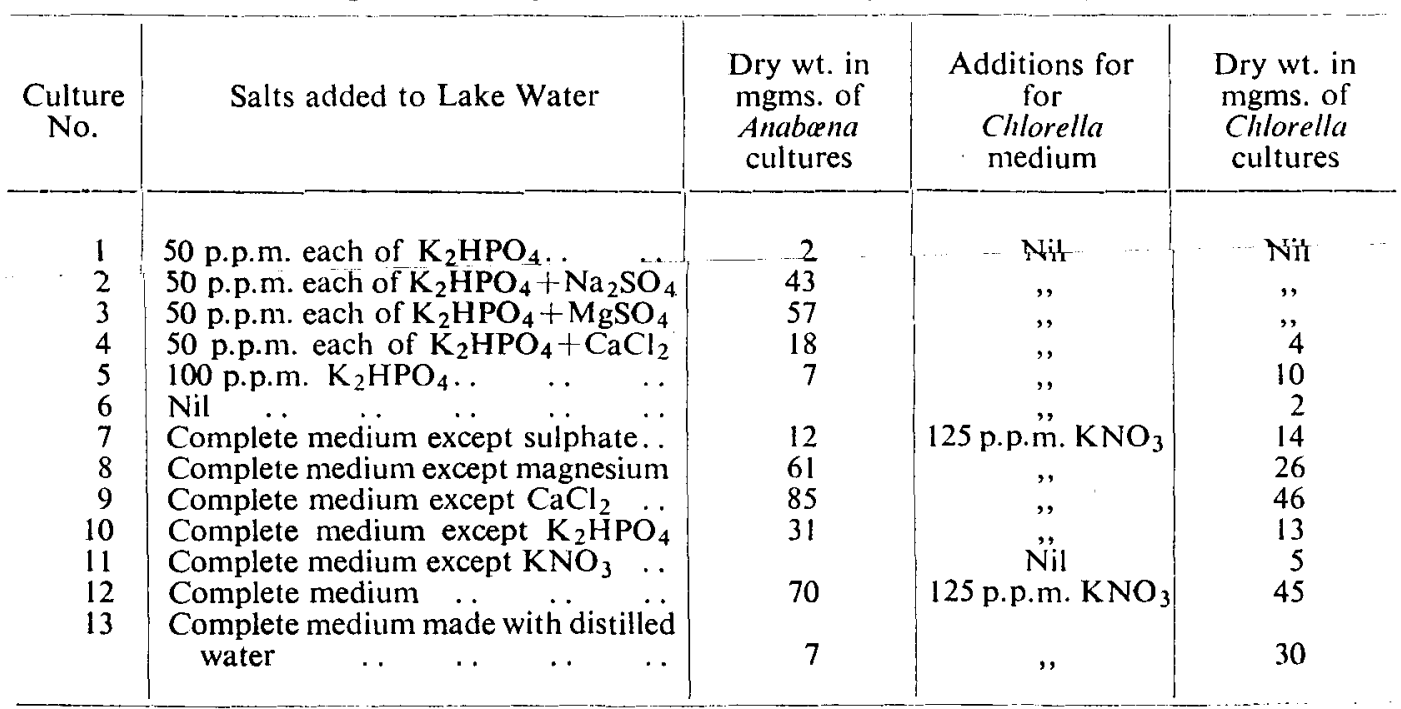


Table 1II.-The Growth of Cultures from 22-4-54 to 10-11-54 in a Lake Water Medium (No precautions were taken to avoid bacterial and fungal contamination)

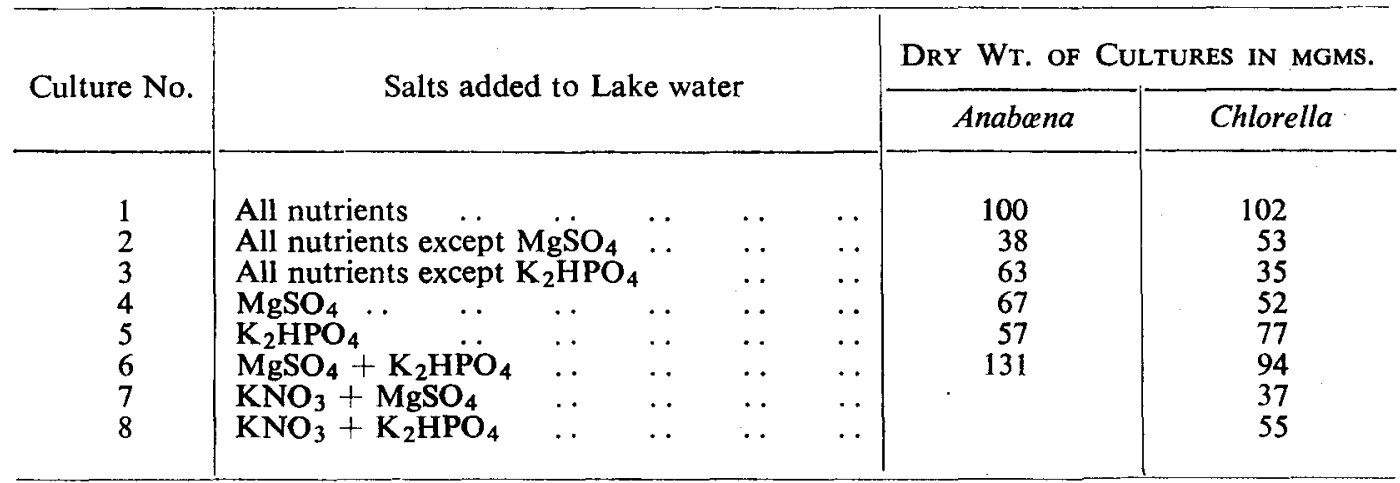

Table IV.--Growth of Algal Culture, 6-2-54 to 24-4-54 in Enriched Lake Water

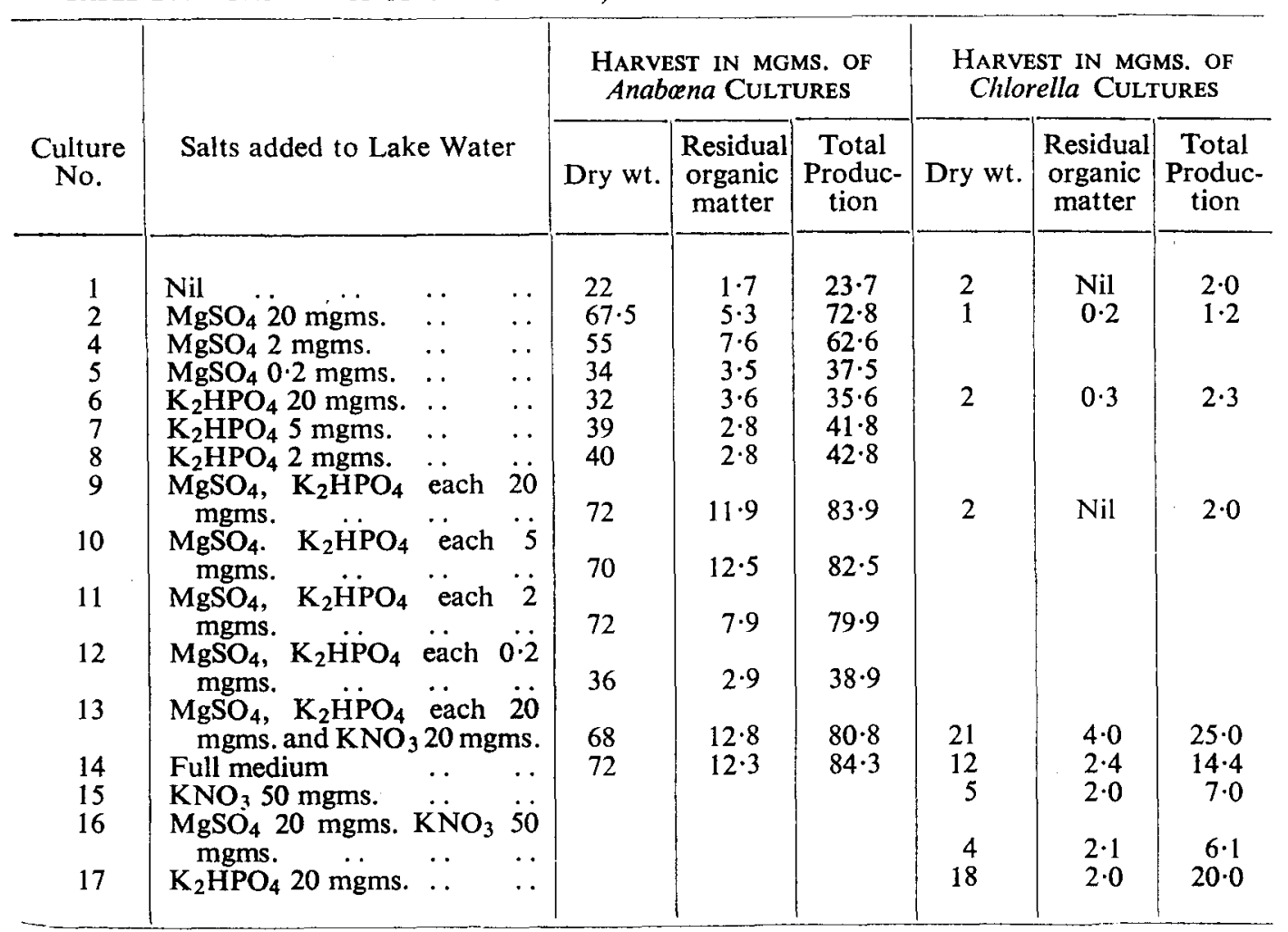


were, in this respect, inconclusive.) In the last recorded experiment (6-2-54), 200 c.c. of lake water were evaporated to dryness in one case and in another these residues were heated until the organic matter was charred. The residues were then each dissolved in 200 c.c. of distilled water. This treatment did not seem to impair the capacity of the medium for growing the test alga. It seems therefore that the growthpromoting properties of the lake water are caused by relatively stable substances.

A few culture experiments were carried out with water samples from Lakes Albert, Rudolf, Bunyoni, George and Edward and from a dam (Jarvis Dam). The growth of cultures in these waters was as poor as it is in unfortified Lake Victoria water, except in the samples from Lake George and from below the thermocline in Lake Edward. These two samples supported a fair growth of both Chlorella and Anabona. A discussion on the reasons for this falls outside the scope of this paper.

\section{CONCLUSIONS}

Attention has already been drawn by Beauchamp [12] to the fact that there appears to be a shortage of soluble sulphates throughout the African continent, and possible reasons were considered. The evidence was based mainly upon chemical analyses of water and soils. The experiments described above show that a shortage of sulphates is likely to be limiting the growth of phytoplankton in Lake Victoria.

Sulphur is an essential constituent of certain amino acids and the phytoplankton may be existing in a marginal concentration of dissolved sulphate. The suggestion has been put forward [12], therefore, that those fish feeding almost wholly on these plants might have a retarded growth rate. The problem may therefore have an economic aspect, for there is an acute shortage of protein in the diet of the local natives, and the most important fishery of Lake Victoria is based on Tilapia species which are plankton feeders [13].

Table V.-The Effect of Lake Water as compared to that of Distilled Water when both ARE USEd for making up Nutrient Culture Solutions. The Favourable Effect of Lake Water, UNIMPAIRED BY MODERATE HEATING, IS SHOWN ESPECIALLY BY THE CULTURES OF Anabana

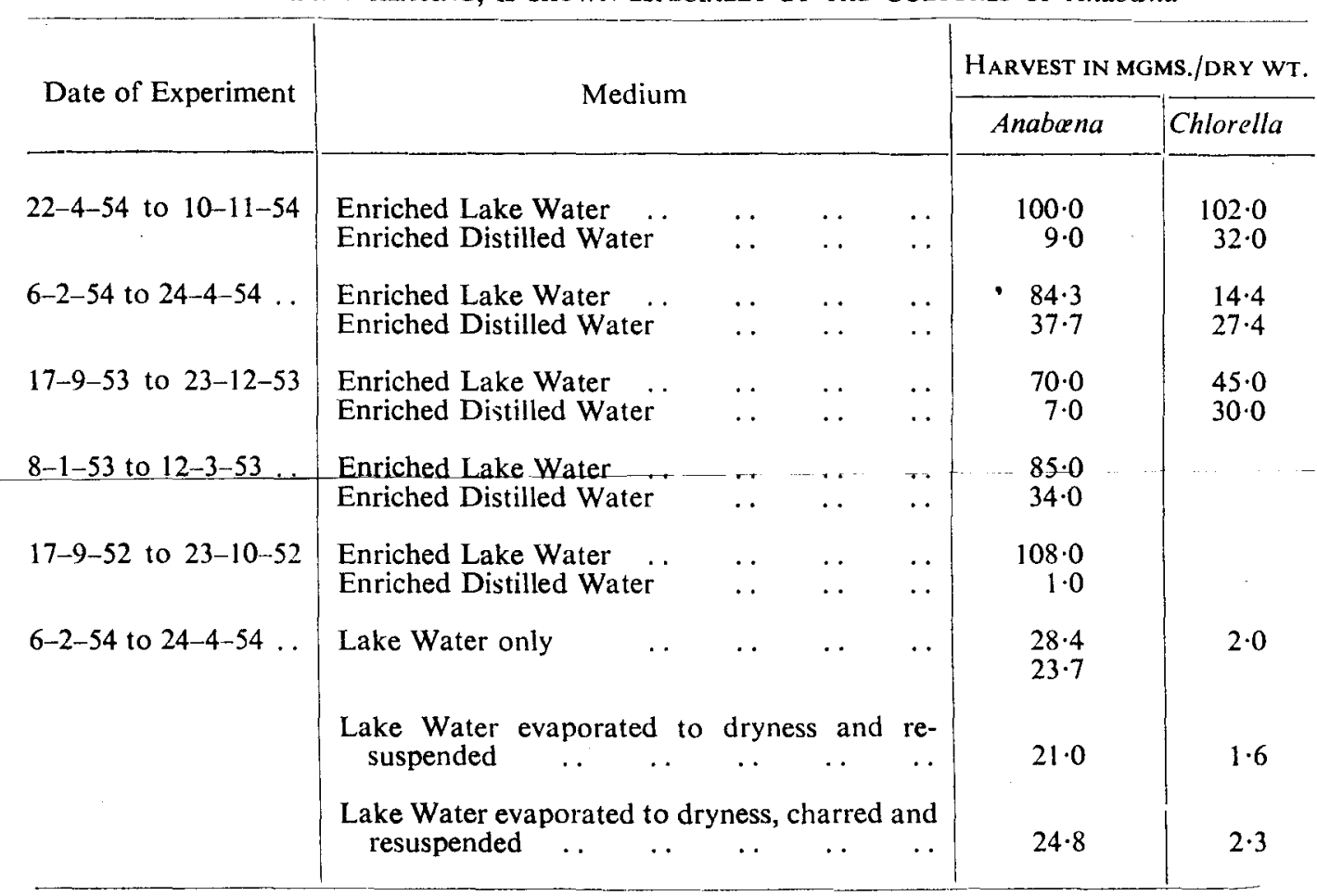


The sulphur cycle is undoubtedly of considerable importance in Lake Victoria. The importance of nitrogen and phosphorus cannot be dismissed, but whereas, during certain periods, phosphate and ammonia have been found in detectable quantities in the lake water, the content of sulphate has never reached this concentration. Fluctuations in sulphate concentration in the lake water are therefore not detectable.

In this lake, the inflows are very small compared to its volume, and the analytical evidence indicates that the supply of sulphate from these sources is likely to be of minor importance. The bottom deposits, after drying, yield comparatively high quantities of sulphate (e.g. 0.25 mgm, per gm. dry weight), but although these would appear to be the obvious main source of supply of sulphates, experiments have failed to show that any considerable quantity is released to the water under natural conditions [14]. The metabolic activity of certain molluses has been shown to cause the release of certain quantities of sulphate into the surrounding water [15]. It is extremely difficult, however, to estimate how significant the activities of these molluscs are to the biology of the lake as a whole, but there would seem to be little doubt that they help to maintain existing levels of fertility.

The culture experiments described in this paper show that, as far as the test alge are concerned, sulphates are a limiting factor for plankton growth as well as nitrates and phosphates. If these conclusions can be confirmed using local phytoplankton species as test algee, then these salts must be regarded as playing a vital role controlling the biological productivity of Lake Victoria.

\section{ACKNOWLEDGMENTS}

I have to thank Dr. G. E. Fogg, University College, London, for a gift of the two original cultures of algæ used here and for much information concerning their mineral requirements.

I would also like to take this opportunity of thanking the Director, E.A. Fisheries Research Organization, for much encouragement and stimulating discussion during the course of these investigations.

\section{REFERENCES}

[I] Ruttner, F. (1953). Fundamentals of Limnology. University of Toronto Press.

[2] Rodhe, W. (1948). Environmental requirements of freshwater plankton algx. Symbolac Bot. Upsal. 10. (1).

[3] Lund, J. W. G. (1950). Studies of Asterionella formosa. Hass II. Nutrient depletion and the Spring maximum. J. Ecol, 38, 1-35.

[4] Hutchinson, G. E. (1944). Limnological studies in Connecticut. VII critical examination of the supposed relationship between phytoplankton periodicity and Chemical Changes in Lake waters. Ecology 25. No. 1.

[5] Riley, G. A. (1941). Plankton studies IV Georges Bank. Bull. Bing Ocean. Coll. 7 Art. 4

[6] Riley, G. A. and Ruth Von Arx. (1949) Theoretical Analysis of seasonal changes in the phytoplankton of Husan Harbor, Korea. Sears Found. J. Marine Research. 8, 50-72.

[7] Mackereth, F. J. (1953). Phosphorus utilization by Asterionella formosa. Hass. J. Exp. Bot. 4, 296313.

[8] East African Fisheries ,Research Organization (1951). Annual Report. Government Printer, Nairobi.

[9] Pringsheim, E. G. (1946). Pure cultures of Alga. Cambridge University Press.

[10] Lerving, T. and Fish, G. R. The penetration of light in some tropical African lakes (in prep.).

(11) Beauchamp, R. S. A. (1953). Sulphates in Africall Inland Waters, Nature, Lond. 17l, 769.

[12] East African Fisheries Research Organization. (1953). Annual Report.

[13] Fish, G. R. (1955). The Food of Tilapia in East Africa. Uganda Journal (in press).

[14] East African Fisheries Research Organization. (1954-5). Annual Report.

[15] Fish, G. R. (1955). Digestion and the Production of sulphuric acid by Mollusca. Nature, Lond. 175,733 .

Table Vi.-The Results of Photosynthesis Experiments Carried out on the 25th August, 1953 near the Centre of Lake George, Uganda. (Total Depth of Station, 3 metres, Water TeMPERATURE $26^{\circ} \mathrm{C}$.)

(Suspensions of the different alga were made and aliquot portions used in 250 ml. oxygen bottles. Exposture for the suspended and dark bottles was from 1100-1200 hours after which period, the dissolved oxygen concentration was estimated and shown as p.p.m.)

\begin{tabular}{|c|c|c|c|c|c|c|c|}
\hline Depth & & 0.5 metres & 1.0 metres & 2.0 metres & 3.0 metres & $\begin{array}{c}\text { Initial } \\
\text { Samples }\end{array}$ & $\begin{array}{c}\text { Dark } \\
\text { Bottles }\end{array}$ \\
\hline $\begin{array}{l}\text { Using Chlorella } \\
\text { Using Anabona } \ldots \\
\text { Using Phytoplankton }\end{array}$ & $\begin{array}{l}\cdots \\
\cdots \\
\cdots\end{array}$ & $\begin{array}{l}3 \cdot 66 \\
4 \cdot 28 \\
4 \cdot 75\end{array}$ & $\begin{array}{l}2 \cdot 92 \\
3 \cdot 95 \\
3 \cdot 41\end{array}$ & $\begin{array}{l}2 \cdot 88 \\
4 \cdot 03 \\
3 \cdot 40\end{array}$ & $\begin{array}{l}2 \cdot 81 \\
4 \cdot 01 \\
3 \cdot 45\end{array}$ & $\begin{array}{l}3 \cdot 38 \\
4 \cdot 00 \\
3 \cdot 94\end{array}$ & $\begin{array}{l}2 \cdot 64 \\
3 \cdot 83 \\
3 \cdot 46\end{array}$ \\
\hline
\end{tabular}

